\title{
Metastatic Carcinoma of Prostate as a Mimicker of SAPHO Syndrome
}

\author{
Rahul Sehgal, MBBS, MD; Andrew R Virata, MD; Pankaj Bansal, MBBS, MD; and Melissa Hart, MD
}

\begin{abstract}
Paraneoplastic arthritides are a group of immune-mediated inflammatory arthropathies associated with occult or manifest malignancy. Musculoskeletal spread of an underlying malignancy may also mimic many rheumatologic conditions. Distinguishing primary rheumatologic condition from paraneoplastic arthritides versus direct musculoskeletal spread of malignancy can be challenging especially in individuals with prior history of cancer and new musculoskeletal complaints. SAPHO (synovitis, acne, pustulosis, hyperostosis and osteitis) syndrome is an uncommon, although under recognized autoimmune disorder. Two musculoskeletal manifestations, namely inflammatory osteitis and hyperostosis of anterior chest wall with or without dermatologic manifestations, constitute a unifying feature of SAPHO syndrome. However, diagnosis of SAPHO syndrome is one of exclusion, and a wide variety of disorders including infections, malignancy (chondrosarcoma/osteosarcoma/ metastasis),metabolic bone disorders (Paget's disease), osteoarthritis,seronegative spondyloarthropathy (spA) and osteonecrosis form part of a broad differential diagnosis. We present the case of a man, aged 72 years, with signs and symptoms of SAPHO syndrome and skin findings. Detailed history, radiological imaging, dermatology appearance, and role of immunohistochemical markers, especially staining for NKX3.I protein with a novel antibody, led to a diagnosis of metastatic prostate adenocarcinoma. To our knowledge, this is the first case of metastatic adenocarcinoma of the prostate manifesting as SAPHO syndrome and cutaneous metastasis.
\end{abstract}

Keywords: SAPHO syndrome; Cancer; Prostate adenocarcinoma

$\mathrm{P}$ araneoplastic arthritides are a group of immune-mediated inflammatory arthropathies associated with an occult or manifest malignancy. ${ }^{1}$ Common entities include paraneoplastic polyarthritis, hypertrophic osteoarthropathy, remitting seronegative symmetrical synovitis with pitting edema, palmar fasciitis and polyarthritis, polyarthritis, and panniculitis associated with pancreatic carcinoma. Musculoskeletal spread of an underlying malignancy may also mimic many rheumatologic conditions. Distinguishing primary rheumatologic conditions from paraneoplastic arthritides versus direct musculoskeletal spread of malignancy can be challenging, especially in individuals with prior history of cancer and new musculoskeletal complaints. SAPHO (synovitis, acne, pustulosis, hyperostosis and osteitis) syndrome is an uncommon, although under-recognized autoimmune disorder. ${ }^{2}$ Musculoskeletal manifestations, namely inflammatory osteitis and hyperostosis of anterior chest wall (ACW) with or without dermatologic manifestations, constitute a unifying feature of SAPHO syndrome. However, diagnosis of SAPHO syndrome is one of exclusion, and a wide variety of disorders including infections, malignancy (chondrosarcoma/osteosarcoma/ metastasis), metabolic bone disorders (Paget's disease), osteoarthritis, seronegative spondyloarthropathy (spA), and osteonecrosis form part of a broad differential diagnosis. ${ }^{3,4} \mathrm{We}$ present the case of a male patient, aged 72 years, with signs and symptoms of SAPHO syndrome and skin findings. Detailed
Corresponding Author: Rahul Sehgal, MBBS, MD, Department of Rheumatology, Mayo Clinic Health System, Eau Claire, WI 54702,

Email: Sehgal.rahul@mayo.edu
Received: June 18, 2020

Revised: March 2, 2021

Accepted: March 24, 2020

doi: $10.3121 / \mathrm{cmr} .2021 .1539$ 




Figure 1. Two friable, bright red/bloody papulonodules on the right medial chest. Few bright pink papules within linear vertical chest scar.

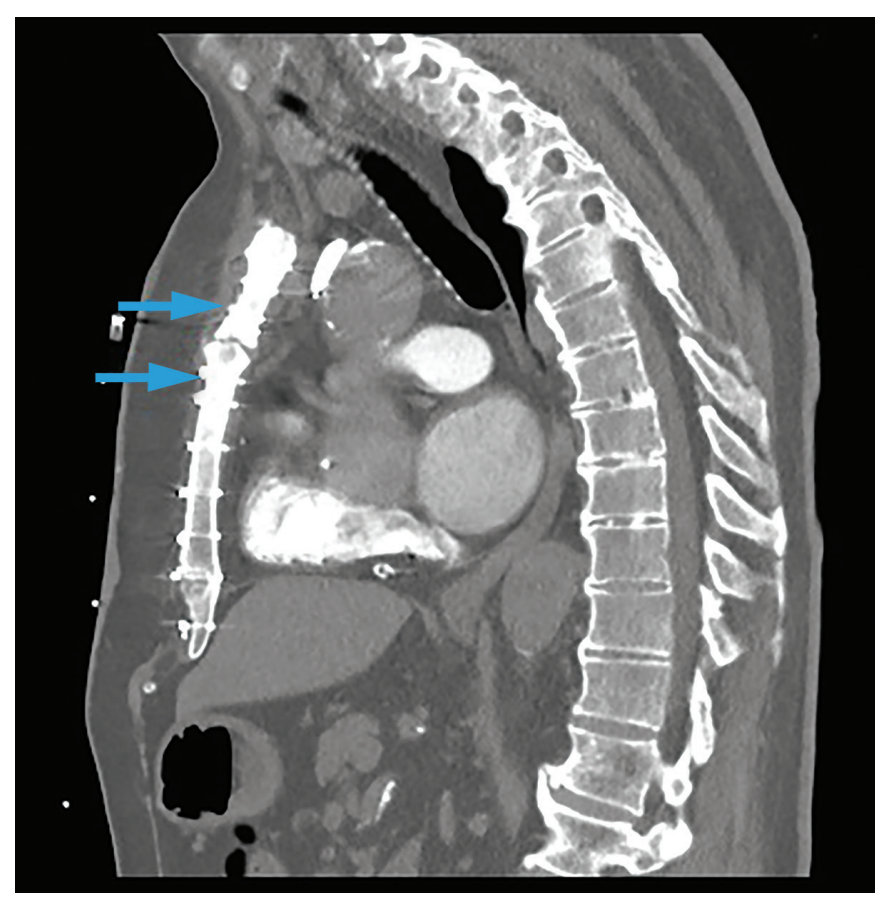

Figure 2. CT chest showing diffuse sclerosis and thickening of sternum and anterior aspect of first ribs bilaterally. history, radiological imaging, dermatology appearance, and role of immunohistochemical markers, especially staining for NKX3.1 protein, led to diagnosis of metastatic prostate adenocarcinoma. The emphasis of our case is to increase awareness of musculoskeletal conditions such as SAPHO syndrome as a manifestation of underlying malignancy. To our knowledge, this is the first case of metastatic adenocarcinoma of the prostate manifesting as SAPHO syndrome and cutaneous metastasis.

\section{Case Report}

A man, aged 72 years, presented to our office with a 6-month history of intermittent retrosternal chest pain radiating along the ribs and 1-month history of ACW skin lesions. The episodic chest pain would last 3-4 days before spontaneously subsiding. On physical examination, edema and tenderness along the sternum, clavicles, sternomanubrial and sternoclavicular joints, as well as anterior margins of $1^{\text {st }}, 2^{\text {nd }}$, and $3^{\text {rd }}$ ribs were present. In addition, there were noted two clinically asymptomatic, friable bright red papulonodular skin lesions on the right medial chest and a few bright pink-red papules within linear vertical chest scar from the previous remote coronary artery bypass graft $(\mathrm{CABG})$ procedure (Figure 1). Past medical history was remarkable for $\mathrm{CABG}$ procedure and hypertension. He had a previous diagnosis of adenocarcinoma of the prostate, Gleason score $9(4+5)$ metastatic to retroperitoneal lymph nodes, 8 years prior. He received treatment with intensity modulated external beam radiation therapy and androgen deprivation therapy completed 7 years prior. He had undetectable prostate specific antigen (PSA) on subsequent follow-ups, including an evaluation 3 months prior. Laboratory studies at this current presentation included normal complete blood count, creatinine, calcium, phosphorus, C-reactive protein $1.7 \mathrm{mg} / \mathrm{L}(\mathrm{nl}<8)$, and erythrocyte sedimentation rate (ESR) $15 \mathrm{~mm} / 1 \mathrm{~h}(\mathrm{nl}<22)$. Elevated alkaline phosphatase (ALP) $345 \mathrm{U} / \mathrm{L}$ (nl 40-29) and bone specific alkaline phosphatase $123 \mathrm{mcg} / \mathrm{L}(\mathrm{nl}<20)$ were noted. Serologies including antinuclear antibody, rheumatoid factor, anti-citrullinated peptide antibody, human leukocyte antigen B27 were negative. A computed tomography (CT) scan of the chest revealed progressive sclerosis and thickening of the sternum and anterior aspect of first ribs, raising suspicion for chronic osteitis such as SAPHO syndrome (Figure 2). A nuclear medicine bone scintigraphy scan revealed intense radiotracer activity involving the manubrium, sternum, and bilateral anterior first through third ribs in a "Bull head" pattern consistent with SAPHO syndrome (Figure 3). PSA was detectable at $0.19 \mathrm{ng} / \mathrm{ml}(\mathrm{nl}<6.5)$. Hyperostosis of ACW in the absence of classic dermatosis associated with SAPHO syndrome prompted further evaluation of atypical SAPHO. CT-guided biopsy of the sclerotic bone from the sternum and manubrium lesion was performed; skin biopsy from the lesion on the anterior chest was also performed. Morphologic features and immunohistochemical stains from bone and skin biopsy were positive for NKX3.1 (Figures 4 and 5) but negative for caudaltype homeobox 2 (CDX2), cytokeratin 7 (CK7), cytokeratin 20 (CK20), paired-box gene 8 (PAX8), PSA, and thyroid 


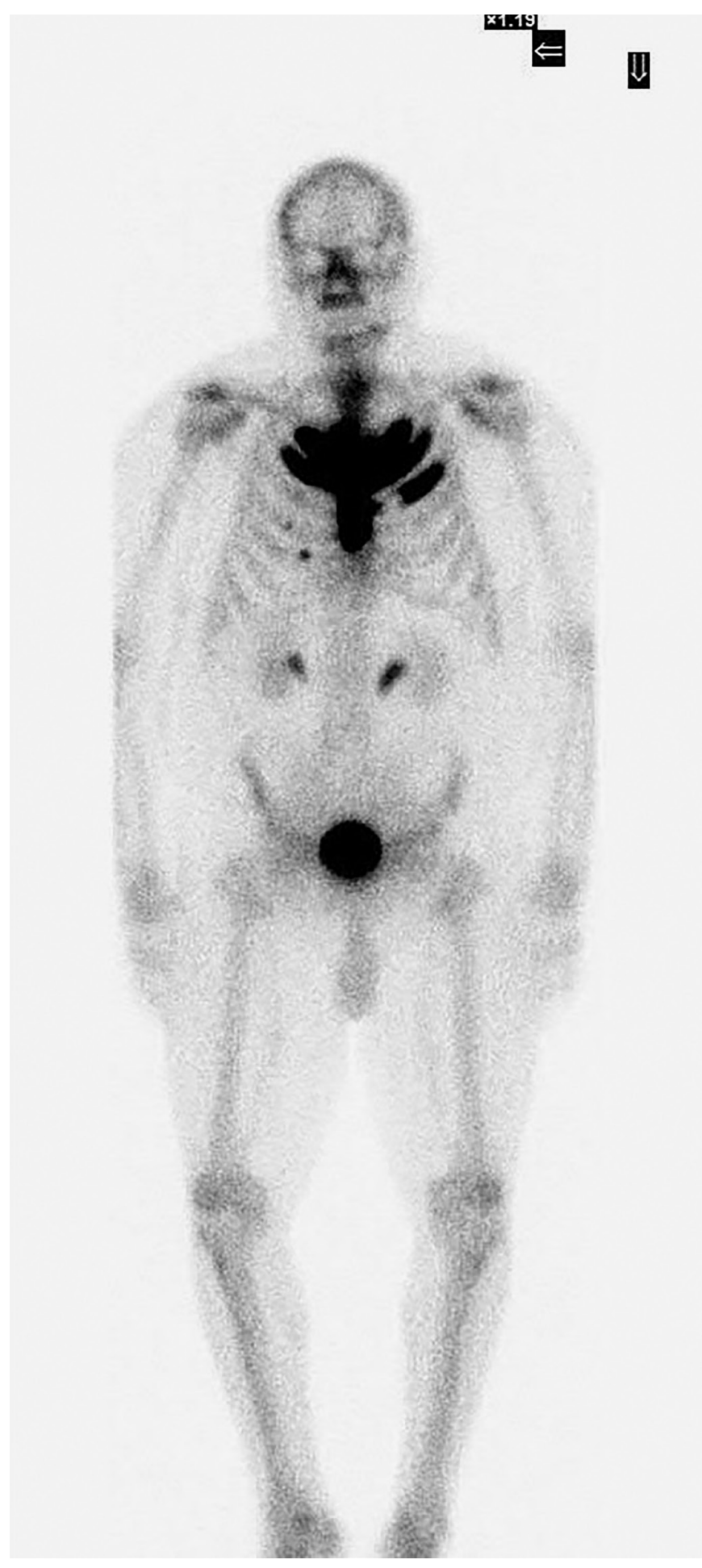

Figure 3. Bone scintigraphy depicting intense tracer activity involving manubrium and sternum and anterior first through third ribs on the left and first through second ribs on the right. The distribution of activity is in a pattern supportive of a diagnosis of SAPHO syndrome. The bone scintigraphy findings also correlate well with findings seen on CT scan. transcription factor-1 (TTF1). Castrate resistant adenocarcinoma of the prostate metastatic to skin and bone was confirmed by morphologic features and immunohistochemical profile of bone and skin biopsy.

\section{Discussion}

Neoplasms can manifest with musculoskeletal and mucocutaneous symptoms/signs that can mimic rheumatic conditions. The rheumatologic condition in question can be a result of direct metastatic spread or represent a paraneoplastic syndrome from immune mechanisms. Cancers of breast, lung, and prostate have a higher tendency to involve bone. These metastatic lesions can be osteolytic (non-small cell lung cancer), osteoblastic (prostate), or both (breast, squamous cell cancer).

Diagnosis of SAPHO syndrome is based on history of ACW symptoms, classic bone scintigraphy finding of "bull head" appearance, radiologic changes of osteitis/hyperostosis and appropriate dermatosis when present; ESR and C-reactive protein are usually normal or only slightly elevated during disease flares. ${ }^{4}$ SAPHO syndrome may present at any age, although it tends to be most common in children and young to middle aged adults. Table 1 presents differential diagnoses (except metastatic spread) of sclerotic bone lesions of ACW.

The most common clinical features of SAPHO syndrome in adults are ACW pain, tenderness, and swelling (aka, ACW syndrome). Sterno-costo-clavicular hyperostosis is a subtype of SAPHO syndrome characterized by hyperactivity at the anterior ends of ribs and hyperostosis of ACW bones on bone scintigraphy, as in this case. Other skeletal sites, in decreasing order of frequency, are the spine and sacroiliac joints, while involvement of the appendicular skeleton is uncommon. ${ }^{5,6}$

Skin involvement may not always coincide with osteoarticular symptoms, and at least $15 \%$ of adults may never experience skin lesions. ${ }^{7,8}$ Palmoplantar pustulosis, severe acne, hidradenitis suppurativa, pyoderma gangrenosum, and Sweet's syndrome are cutaneous manifestations of SAPHO syndrome, in deceasing order of frequency.

Skeletal complaints tend to precede development of skin lesions by up to 2 years in the majority of patients, as seen in our case. Pain from inflammatory osteitis of anterior thoracic wall can be quite disabling, prompting symptomatic treatment with non-steroidal anti-inflammatory drugs and intravenous bisphosphonates; in refractory cases, biologic therapies have been utilized with variable success. ${ }^{9}$ Other presentations include inflammatory back pain (frequently unilateral sacroiliitis) and peripheral joint involvement from a pseudoseptic process. Although uncommon in adults, long bones such as tibia and femur tend to be more commonly affected in children. While a whole bone scintigraphy finding of "bull's head" distribution of increased tracer uptake is considered 
Table 1: Differential diagnosis (except metastatic spread) of sclerotic bone lesions of anterior chest wall

\begin{tabular}{|c|c|c|}
\hline Entity & Diagnostic clues & Radiologic features \\
\hline $\begin{array}{l}\text { Radiation induced } \\
\text { bone changes }\end{array}$ & $\begin{array}{ll}\text { - } & \text { past radiation therapy } \\
\text { - } & \text { bone changes confined to radiation field } \\
\text { - } & \text { soft tissue mass } \\
\text { - } & \text { Rare with IMRTa }\end{array}$ & $\begin{array}{l}\text { - Osteoradionecrosis/osteopenia/altered bone } \\
\text { architecture/ pathologic fracture/radiation } \\
\text { induced bone neoplasms }\end{array}$ \\
\hline Paget's disease & $\begin{array}{l}\text { - } \quad \text { Slight male predilection } \\
\text { - } \quad \text { Asymptomatic }(75 \%) \\
\text { - } \quad \text { temperature, bone size and bone deformity } \\
\text { - } \quad \text { Increasphorus } \\
\text { - } \quad \text { Common }{ }^{b}, \text { normal Calcium and } \\
\quad \text { long bones. Rare in ribs, clavicle and sternum }\end{array}$ & $\begin{array}{l}\text { - Lucent regions, coarse trabeculae, thick } \\
\text { cortex, bone enlargement followed by } \\
\text { sclerotic changes. } \\
\text { - Bone scintigraphy: increased uptake except } \\
\text { in burnt out sclerotic phase (normal uptake) }\end{array}$ \\
\hline $\begin{array}{l}\text { Seronegative } \\
\text { spondyloarthritis } \\
\text { (spA) }\end{array}$ & $\begin{array}{l}\text { - Inflammatory back pain, HLA B27+ }>85 \% \text {, } \\
\text { elevated } \mathrm{CRP}^{\mathrm{c}} \text {. } \\
26 \% \text { have clinical involvement of } \mathrm{ACW}^{\mathrm{d}} \text { and } \\
44 \% \text { have imaging evidence of } \mathrm{ACW} \\
\text { inflammation }\end{array}$ & $\begin{array}{l}\text { - Marginal syndesmophytes, bone marrow } \\
\text { edema and erosions around sternoclavicular } \\
\text { or sternomanubrial joints }\end{array}$ \\
\hline $\begin{array}{l}\text { Neoplasm of } \\
\text { sternum }\end{array}$ & $\begin{array}{l}\text { - Chondrosarcoma: most common primary } \\
\text { malignant tumor of sternum; 4th-6th decade of } \\
\text { life, male predilection, large and painless ACW } \\
\text { mass (slow growing) } \\
\text { - Osteosarcoma: painful bone mass, median age } \\
\text { of } 42 \text {, rare in }>65\end{array}$ & $\begin{array}{l}\text { - Irregularly shaped sclerotic mass from } \\
\text { superior sternal body }\end{array}$ \\
\hline SAPHO syndrome & $\begin{array}{l}\text { - } \quad \text { Chronic onset } \\
\text { - } \quad \text { Age: children and young to middle age } \\
\text { - } \quad \text { ACW syndrome }\end{array}$ & $\begin{array}{l}\text { - Hyperostosis involving bones and synovitis } \\
\text { of joints of anterior chest wall }\end{array}$ \\
\hline $\begin{array}{l}\text { Enostosis (bone } \\
\text { island) }\end{array}$ & $\begin{array}{l}\text { - } \quad \text { Asymptomatic, incidental findings. } \\
\text { - } \quad \text { No treatment necessary }\end{array}$ & $\begin{array}{l}\text { - } \quad \text { Compact bone inside cancellous bone } \\
\text { - } \quad \text { No uptake on bone scintigraphy (cf: } \\
\text { metastasis) }\end{array}$ \\
\hline $\begin{array}{l}\text { Infectious: chronic } \\
\text { osteomyelitis }\end{array}$ & $\begin{array}{l}\text { - } \quad \text { Chest wall swelling, pain and tenderness. } \\
\text { - } \quad \text { Chest wall mass } \\
\text { trauma or cardiac surgery }\end{array}$ & $\begin{array}{l}\text { - Increased bone scintigraphy uptake in and } \\
\text { around affected bone/joint } \\
\text { Sclerosis of sternum/manubrium, } \\
\text { sternomanubrial joint and sinus tracts }\end{array}$ \\
\hline Osteoarthritis & - $\quad$ Chronic, with or without symptoms & $\begin{array}{l}\text { - Subchondral cysts and sclerosis, osteophyte } \\
\text { formation and joint space narrowing of } \\
\text { sternoclavicular and sternomanubrial joints }\end{array}$ \\
\hline
\end{tabular}

aMRT, Intensity modulated radiation therapy; ${ }^{\mathrm{b}} \mathrm{ALP}$, alkaline phosphatase; ' $\mathrm{CRP}, \mathrm{C}$-reactive protein; ${ }^{\mathrm{d} A C W}$, anterior chest wall; e CT, computed tomography; fSAPHO, synovitis, acne, pustulosis, hyperostosis and osteitis; gHIV, human immundeficiency virus; ' IVDU, intravenous drug use

pathognomic for SAPHO syndrome, it is not a very sensitive test by itself.

Bone represents the most common site of metastatic spread for adenocarcinoma of the prostate, while cutaneous metastases occur in $<1 \%$ of cases ${ }^{10}$ Metastasis to skin occurs in $<10 \%$ of patients with an underlying malignancy and is associated with a dismal prognosis. Immunohistochemical markers are useful adjuncts in the diagnosis of prostate carcinoma, especially in poorly differentiated metastatic cancers and in cases of metastatic carcinoma from uncertain primary sites. ${ }^{11}$ PSA and prostatic-specific acid phosphatase (PSAP) are excellent tissue markers of prostate cancer. Although the sensitivity of PSA and PSAP are $94.2 \%$ and $98.6 \%$, respectively, their expression in poorly differentiated and metastatic disease can be low or completely absent. NKX3.1 is a prostate tumor 


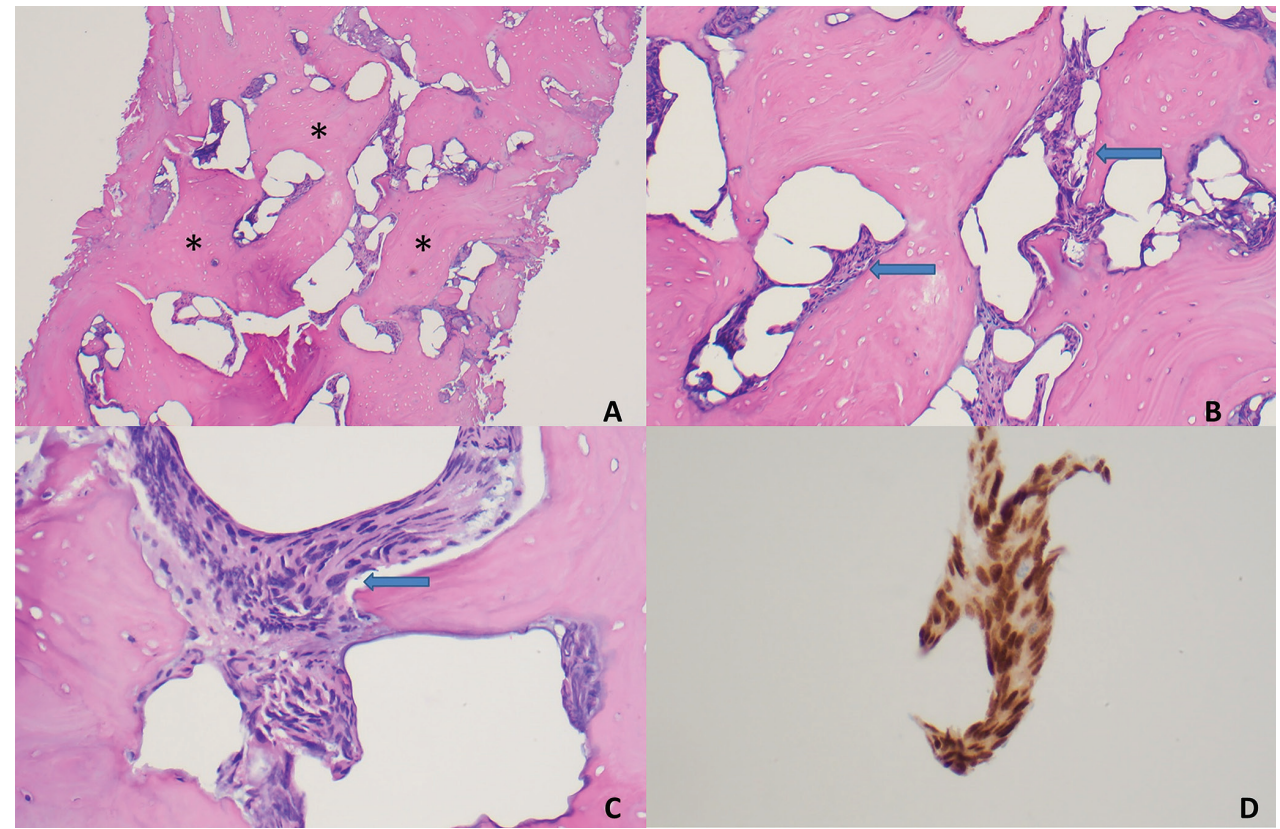

Figure 4. Histopathology findings of bone biopsy. (A) Microscopic examination of the core needle biopsy at low power (4x objective) reveals markedly thickened bony trabeculae (indicated by *) with a paucity of marrow space. (B) On higher power (10x objective), an infiltrate of epithelioid cells with crush artifact is apparent (blue arrow). (C) On 20x objective magnification, the epithelioid cells along the bony trabeculae can be clearly visualized. (D) By immunohistochemistry, these cells were positive for NKX3.1, consistent with metastatic adenocarcinoma of prostatic origin.
Alarming features in our case that triggered an intense search for malignancy include prior history of prostate cancer, our patient's advanced age, atypical skin findings, and evidence of osteoblastic lesions with elevated alkaline phosphatase. Distinguishing SAPHO syndrome from malignancy can be challenging, especially in individuals with known history of cancer. A PubMed search of the English literature using search terms 'SAPHO syndrome', 'cancer', and 'malignancy' was conducted. In a majority of case reports, SAPHO syndrome was diagnosed coexistent with an underlying cancer. Cases of SAPHO syndrome with ileal osteosarcoma, ${ }^{15}$ pancreatic hamartoma, ${ }^{16}$ pulmonary adenocarcinoma (both small cell and nonsmall cell types), ${ }^{17,18}$ breast cancer, ${ }^{19}$ and bladder cancer ${ }^{20}$ have been reported. In other cases, metastatic disease from a suspected unknown primary was investigated in newly diagnosed case of SAPHO syndrome. ${ }^{21}$ suppressor gene located on chromosome $8 \mathrm{p}$. Expression of NKX3.1 is predominantly localized to prostate epithelium. ${ }^{12}$ Staining for antibody to NKX3.1 protein is highly sensitive $(98.6 \%)$ and specific (99.7\%) for diagnosis of castration resistant prostatic adenocarcinoma. ${ }^{13}$ In addition, staining for NKX3.1 protein is retained in poorly differentiated or metastatic adenocarcinoma of prostate compared with PSA and PSAP, ${ }^{14}$ as was also seen in our case.
In a few of these cases, sternum/manubrium bone biopsy had been utilized, revealing nonspecific inflammation seen with SAPHO syndrome composed of polymorphonuclear cells, monocytes, and bone remodeling/bone marrow fibrosis. ${ }^{22}$ Others have utilized F-18 fluorodeoxyglucose positron emission tomography/computed tomography (18FDG- PET/CT) to help distinguish inflammatory osteitis/hyperostosis in SAPHO


Figure 5. Histopathology findings of skin biopsy. (A) Hematoxylin and eosin stain, low power (2x magnification), demonstrates dermal tumor cell aggregates with glandular lumen formation (single arrows). (B) Hematoxylin and eosin stain, intermediate power (20x magnification), demonstrates enlarged tumor cells with pleomorphic nuclei and prominent nucleoli (single arrow), glandular lumen formation (double arrow), and stromal blood vessels (triple arrow). (C) NKX 3.1 immunohistochemical stain, low power (2x magnification), demonstrates positive staining of dermal tumor cells. 
syndrome from suspected metastasis. ${ }^{23}$ Findings of increased FDG activity localized to joints (suggestive of synovitis seen with SAPHO) rather than to bone lesions (indicative of metastasis) are helpful. In addition, absence of FDG activity at sites of tracer uptake on bone scintigraphy helps to exclude metastasis..$^{24}$

Although the utility of sternal/manubrium biopsy has been questioned in evaluation of SAPHO syndrome, ${ }^{19}$ our case highlights that such a decision should be individualized. In those with a history of malignancy, even in the distant past, bone biopsy or F18 FDG-PET CT should be considered to exclude skeletal metastasis. In one other case of SAPHO syndrome-like appearance on bone scintigraphy, biopsy of the left clavicle led to diagnosis of metastatic breast cancer rather than inflammatory osteitis from SAPHO syndrome. ${ }^{25}$ In their case, $\mathrm{Ni}$ and Tang ${ }^{25}$ describe a woman, aged 47 years, with a history of invasive ductal carcinoma of the breast who underwent left radical mastectomy 3 years earlier and presented with typical bone scintigraphy findings of bull horn appearance upon investigation for ACW pain. In addition to elevated ALP, the patient also had elevated ESR. A bone biopsy from the left clavicle confirmed presence of metastatic adenocarcinoma of breast.

\section{Management}

Our patient was diagnosed with non-secretory, castration resistant prostate cancer metastatic to bone and skin. He was not felt to be a candidate for chemotherapy due to comorbidities, and palliative treatment to improve symptoms and prolong survival was initiated. A single fraction of radiation to the sternum (800 cGy) was well tolerated, and his ACW pain/ tenderness improved. He began treatment with bicalutamide (anti-androgen) and leuprolide (gonadotropin releasing hormone agonist) followed by abiraterone (androgen deprivation therapy), low dose prednisone, and monthly denosumab. In follow-up at 6 months, the patient had improvement in skin lesions and continued response to chest wall discomfort. His ALP normalized, and he continues follow-up care with oncology.

\section{Conclusion}

Metastatic cancers may mimic SAPHO syndrome, especially when involving uncommon sites such as anterior chest wall and skin. Bone biopsy is useful to exclude malignancy, especially in those with known history of malignancy.

\section{References}

1. Manger B, Schett G. Rheumatic paraneoplastic syndromes- a clinical link between malignancy and autoimmunity. Clin Immunol. 2018;186:67-70.

2. Chamot AM, Benhanou CL, Kahn MF, Beraneck L, Kaplan G, Prost A. Acne-pustulosis-hyperostosisosteitis syndrome. Results of a national survey. 85 cases. [Le syndrome acne pustulose hyperostose osteite. Resultats d'une enquete nationale; 85 observations.] Rev Rhum Mal Osteoartic.1987;54(3):187-196. [Article in French].
3. Benhamou CL, Chamot AM, Kahn MF. Synovitisacne-pustulosis hyperostosis-osteomyelitis syndrome (SAPHO). A new syndrome among the spondyloarthropathies? Clin Exp Rheumatol. 1988;6(2):109-112.

4. Colina M, Govoni M, Orzincolo C, Trotta F. Clinical and radiologic evolution of synovitis, acne, pustulosis, hyperostosis, and osteitis syndrome: a single center study of a cohort of 71 subjects. Arthritis Rheum. 2009;61(6):813-821.

5. Earwaker JW, Cotten A. SAPHO: syndrome or concept? Imaging findings. Skeletal Radiol. 2003;32(6):311-327.

6. Depasquale R, Kumar N, Lalam RK, et al. SAPHO: What radiologists should know. Clin Radiol. 2012;67(3):195-206.

7. Hayem G, Bouchaud-Chabot A, Benali K, et al. SAPHO syndrome: a long-term follow-up study of 120 cases. Semin Arthritis Rheum. 1999;29(3):159171.

8. Sallés M, Olivé A, Perez-Andres R, et al. The SAPHO syndrome: a clinical and imaging study. Clin Rheumatol. 2011;30(2):245-249.

9. Rothschild B, Schils J, Lavelle H. Potential therapeutic approach to SAPHO. Semin Arthritis Rheum. 2000;29(5):332-334.

10. Schwartz RA. Cutaneous metastatic disease. J Am Acad Dermatol. 1995;33(2 Pt 1):161-186.

11. Varma M, Jasani B. Diagnostic utility of immunohistochemistry in morphologically difficult prostate cancer: review of current literature. Histopathology. 2005;47(1):1-16.

12. Abate-Shen C, Shen MM, Gelmann E. Integrating differentiation and cancer: the Nkx3.1 homeobox gene in prostate organogenesis and carcinogenesis. Differentiation. 2008;76(6):717-727.

13. Gurel B, Ali TZ, Montgomery EA, et al. NKX3.1 as a marker of prostatic origin in metastatic tumors. Am J Surg Pathol. 2010;34(8):1097-1105.

14. Chuang AY, DeMarzo AM, Veltri RW, Sharma RB, Bieberich CJ, Epstein JI. Immunohistochemical differentiation of high-grade prostate carcinoma from urothelial carcinoma. Am J Surg Pathol. 2007;31(8):1246-1255.

15. Legrand E, Audran M, Rousselet-Chapeau MC, et al. Iliac osteosarcoma in a patient with SAPHO syndrome. Rev Rhum Engl Ed. 1995;62(2):139-141.

16. Sampelean D, Adam M, Muntean V, Hanescu B, Domsa I. Pancreatic hamartoma and SAPHO syndrome: a case report. J Gastrointestin Liver Dis. 2009;18(4):483-486.

17. Imamura K, Sakata S, Sakamoto Y, Saeki S. Small-cell Lung Cancer Associated with SAPHO Syndrome. Intern Med. 2018;57(1):149-151. 
18. Shibakuki R, Seto T, Uematsu K, et al. Pulmonary adenocarcinoma associated with SAPHO syndrome difficult to differentiate from multiple bone metastasis. Intern Med. 2006;45(8):543-546.

19. Berenguer Francés MÁ, Lafaurie Acevedo A, Tormo Ferrero V, Cardenal Macia R, Andreu Martínez FJ. SAPHO syndrome in the differential diagnosis of metastasis. Síndrome de SAPHO como diagnóstico diferencial de metástasis. Reumatol Clin. 2016;12(5):288-291.

20. Matsumaru K, Nagai K, Murakami T, Andoh K. SAPHO syndrome with bacillus Calmette-Guerin (BCG) immunotherapy for bladder cancer. BMJ Case Rep. 2010;2010:2591.

21. Abuhid IM, Silva LC, Martins GP, de Rezende NA. Diagnosing SAPHO syndrome in suspected metastatic bone tumors. Clin Nucl Med. 2010;35(3):172-174.

22. Theumann NH, So A, Mouhsine E, et al. SAPHO syndrome masquerading as metastatic bone disease. Australas Radiol. 2005;49(5):418-421.

23. Patel CN, Smith JT, Rankine JJ, Scarsbrook AF. F-18 FDG PET/CT can help differentiate SAPHO syndrome from suspected metastatic bone disease. Clin Nucl Med. 2009;34(4):254-257.

24. Pichler R, Weiglein K, Schmekal B, Sfetsos K, Maschek W. Bone scintigraphy using Tc-99m DPD and F18-FDG in a patient with SAPHO syndrome. Scand J Rheumatol. 2003;32(1):58-60.

25. Ni J, Tang P. An Unusual Bone Metastasis Mimicking SAPHO (Synovitis, Acne, Pustulosis, Hyperostosis, and Osteitis) Syndrome on Bone Scintigraphy. Clin Nucl Med. 2016;41(2):173-175.

\section{Author Affiliations}

Rahul Sehgal MBBS, MD*; Andrew R Virata, MD'; Pankaj Bansal, MBBS, MD; Melissa Hart, $M D^{\S}$

*Department of Rheumatology, Mayo Clinic Health System, Eau Claire, WI 54702

'Department of Laboratory medicine and Pathology, Mayo Clinic Health System, Eau Claire, WI 54702

Department of Rheumatology, Mayo Clinic Health System, Eau Claire, WI 54702

${ }^{\S}$ Department of Laboratory medicine and Hemato-pathology, Mayo Clinic Health System, Eau Claire, WI 54702 